\title{
Talc-Based Concrete for Sealing Borehole Optimized by Using Particle Packing Theory
}

\author{
Mohammed Hatem Mohammed ${ }^{1,2}$, Roland Pusch $^{1}$, Nadhir Al-Ansari ${ }^{1}$, Sven Knutsson ${ }^{1}$, Mats Emborg ${ }^{1}$, Martin \\ Nilsson $^{1}$ and Alireza Pourbakhtiar ${ }^{1}$ \\ 1. Department of Civil, Mining and Natural Resources Engineering, Lulea University of Technology, Lulea 97187, Sweden \\ 2. Department of Civil Engineering, College of Engineering, Mosul University, Mosul 41002, Iraq
}

\begin{abstract}
The paper describes assessment of the performance of cement-poor concretes on the basis of packing theory. The concretes are intended for sealing segments of deep boreholes and have a small amount of cement for minimizing the mutual chemical impact on the contacting clay seals. The composition is examined by application of packing theory with respect to the cement/aggregate ratio and the gradation of the aggregate material which is crushed quartzite for providing high internal friction after maturation, as well as to talc added for fluidity and to the small amount of cement. Low porosity and micro-structural stability must be guaranteed for very long periods of time. The study exemplifies how packing theory assist designers in selecting optimal proportions of the various components. Optimum particle packing implies minimizing the porosity and thereby reducing the amount of cement paste needed to fill the voids between the aggregate particles. The use of talc as inorganic super-plasticizer since ordinary organic additives for reaching high fluidity at casting are undesirable, and since talc reacts with cement and provides high strength in along-term perspective.
\end{abstract}

Key words: Packing theory, concrete, strength, talc mineral, micro-structural modeling.

\section{Introduction}

A proposed technique of sealing deep boreholes by installing clay plugs where the rock is poor in fractures, and casting concrete where the boreholes intersect fracture zones was initially developed for deep exploration boreholes but is applicable to a number of other cases [1]. The role of the concrete is to support the clay plugs throughout the borehole and at either end and to serve as filter for preventing clay particles to migrate through it out into the fracture zone and further out into the rock. Fig. 1 shows a schematic profile of a sealed borehole.

In order to provide stable conditions in the borehole throughout the installation of the various seals fracture zones need to be secured. The techniques and methods have been considered by various organizations and the proposed technique is to make selective stabilization

Corresponding author: Mohammed Hatem Mohammed, Ph.D. student, research field: structural engineering. E-mail: Mohammed.Hatem@ltu.se. by reaming, from $76 \mathrm{~mm}$ to $98 \mathrm{~mm}$ diameter for typical boreholes, followed by casting concrete between packers for achieving a stable "concrete tube” after re-drilling [2]. The principle is shown in Fig. 2.

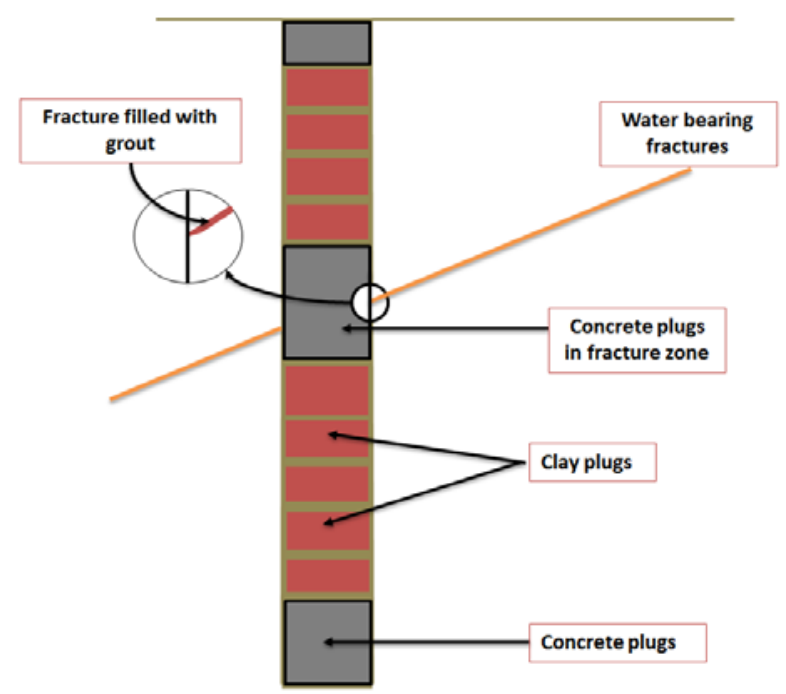

Fig. 1 Borehole profile, grout is used for reducing the inflow of water into the hole from fracture zones and for stabilizing it. 


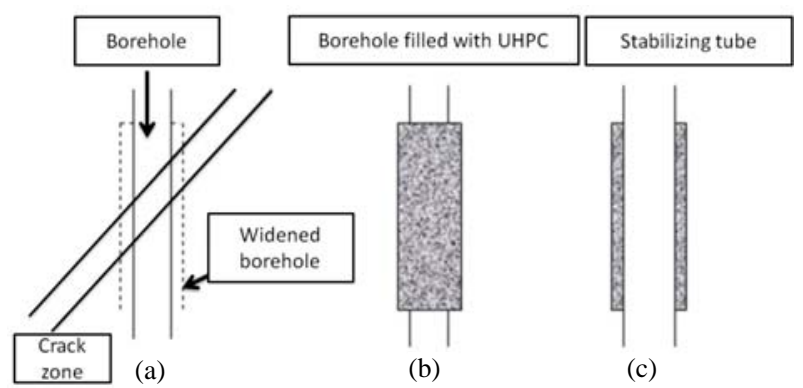

Fig. 2 Technique for stabilizing boreholes: (a) borehole intersecting fracture zone; (b) reamed hole filled with concrete between packers; (c) re-boring giving a stabilized hole.

\section{Principles of Sealing Deep Boreholes}

The clay is proposed to be smectite-rich and to have a high density since this gives it a hydraulic conductivity that is much lower than that of the rock matrix and an expandability that is sufficient to create high wall friction and to eliminate the risk of water flow along the contact with the rock [3]. The clay seals consist of highly compacted smectite clay ("bentonite”) fitted in perforated copper tubes (Fig. 3) placed on concrete seals cast where fracture zones are intersected. Clay swells out through the perforation and forms a tight skin between the tubes and the rock in less than a day and completely closes and seals off the borehole. The technique has been tested and applied in several large-scale projects [4].

The concrete should contain very little cement for minimizing the clay-degrading impact of $\mathrm{pH}$ in the groundwater caused by cement. It therefore does not generate significant adhesion to the rock or significant wall friction. The concrete presently intended for borehole sealing matures slowly depending on the types of cement and super-plasticizer and may not harden until after one week. Before this it performs as a viscous-plastic substance with substantial internal friction. Assuming that there is direct contact between concrete and clay a swelling pressure of a few MPa will ultimately be exerted by the clay seals on the contacting concrete.

The proposed silica-rich concrete with cement that

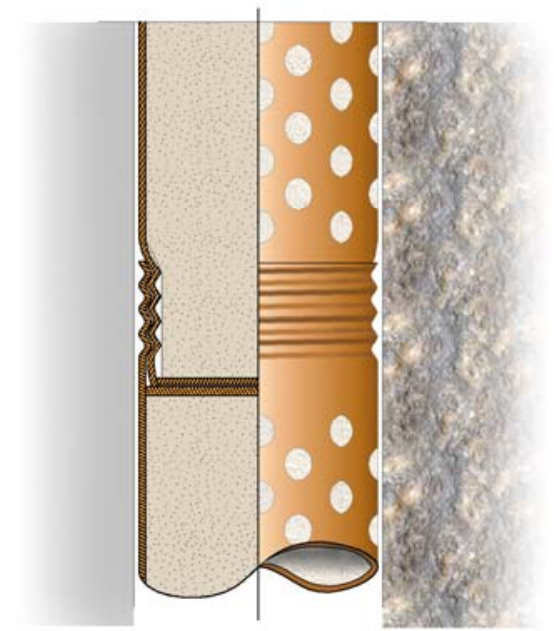

Fig. 3 Perforated copper tube with highly compacted smectite clay, tubes are jointed to form long segments that are inserted in the holes (drawing by Sweco Int. Co.).

can be of Portland types or of low-pH type and contain ordinary super-plasticizer type Glenium 52, or talc for making it sufficiently fluid. It will be cast under water using closed containers as demonstrated in full scale [3]. This type of concrete is largely inert with respect to chemical interaction with smectite clay and can be allowed to lose the cement component without jeopardizing its function as fill by utilizing a size distribution of the aggregate grains that prevents the large majority of the clay particles to migrate into the rock fractures. This risk is largely eliminated by stabilizing the intersected fracture zones as described in Fig. 1 and preceding grouting. Stabilization and subsequent clearing and cleaning of borehole walls are necessary prerequisites for successful plugging, which comprises segment-wise placement of clay plugs and casting of concrete. The upper end of boreholes extending from the ground surface needs an upper "mechanical" seal for which copper metal and concrete work can be employed [3].

\section{Composition and Constitution of Proposed Concrete Seals}

\subsection{Principles}

The concrete seals to be cast in boreholes should have a small amount of cement for minimizing the 
mutual chemical impact on the contacting clay seals. This can be achieved by keeping the cement/aggregate ratio very low and by using aggregate material with high internal friction after maturation, and also by using low-pH cement. The properties of main constituent particulate composite materials, concrete for instance will determine of their behavior and properties. Aggregate are the main constituent of concrete, which represent about $75 \%$ of the total volume mixture. The performance of concrete in both fresh and hardened states affected by the texture, shape and grading of aggregate. High aggregate packing density has smaller void volume which needs low amounts of paste to fill these voids and this will lead to decreasing the cost and less the problems caused by paste like creep, drying shrinkage and high hydration [5]. One of the most important techniques controls the performance of concrete is the particle packing theory, which in role influencing by the particle size distribution of aggregate. Packing density can optimize concrete by combining available aggregate and make it as dense as possible with keeping the workability of concrete in acceptable level. A recommended principle in composing concrete for sealing boreholes, followed also in the present project, is therefore to reduce the cement content by application of packing theory to an absolute minimum since even total loss would have a very small impact on the porosity and hydraulic conductivity. The ideal concrete recipe means: (1) increased compressive strength with time; (2) good workability and fluidity; (3) minimum cement gives low cost; (4) minimum cement and ideal granular composition brings about low compressibility and hydraulic conductivity.

This article presents the results of an experimental study on the fresh and hardened of concrete and their relation with mixture packing density. Casting of concrete with high packing density requires addition of super-plasticizers, which are commonly of organic type. Since they can release organic colloids with a potential to transport radionuclides up to the biosphere attempts are made to find chemically compatible, inorganic additives and a candidate material, fine-grained talc has been used in pilot testing of concrete for use in boreholes. For obtaining optimal packing density of aggregates it had been used of validated model provides a general basis for alternative aggregate combinations. This implying that can give the designers a wide range for selecting the best of several possible aggregate size spectra and hence to a cheaper concrete with improved quality without comprehensive testing. Validated models will reduce the high number of experiments required for verification the recipe in practice. High $\mathrm{pH}$ of concrete provided by ordinary portland cement, which can degrade contacting clay seals by cation exchange and substitution reactions [6]. Suitable binder can be low-pH cement, the present study included investigation based on packing concept of the properties of talc-concretes with similar aggregate compositions, based on Portland and low-pH cement of type Merit 5000, respectively.

\subsection{Micro-structural Co-ordination}

A suitable concrete recipe shall be worked out with respect to (1) the need of keeping $\mathrm{pH}$ as low as possible; (2) making the aggregate component as dense as possible; and (3) selecting very quartz-rich aggregate material. Such search is ongoing but at present it seems that aggregate of crushed quartzite is best and that a minimum amount of cement is the second most important principle. Organic plasticizers will not be allowed for use in repositories for highly radioactive waste and mineral talc is considered and assumed to serve acceptably. Modeling for calculating important micro-structural parameters has been made following the principle illustrated in Fig. 4 [7].

\subsubsection{Application of Packing Theories}

Concrete behavior is affected by the packing degree of the concrete components, making it necessary for engineers to consider, in detail, particle packing concepts and their influence on concrete behavior for 


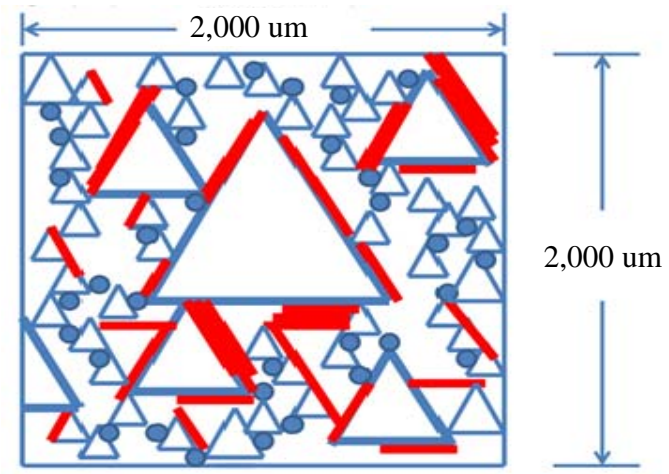

Fig. 4 Schematic view of REV (representative elementary volume) of talc concrete in $2 \mathrm{D}$, it represents aggregate pattern with cement grains (grey spheres) and talc particles (thick red lines), the section is taken to be $400 \mu \mathrm{m}$ thick and hosts aggregate grains representing the size fractions $0.8-1$ $\mathrm{mm}, 0.4-0.8 \mathrm{~mm}$ and $0-0.4 \mathrm{~mm}$, the cement grains are assumed to be $20 \mu \mathrm{m}$ in diameter, the talc particles are assumed to cover the whole side surface of the indicated aggregate grains and be $100 \mu \mathrm{m}$ thick in average.

selecting suitable fine-aggregate material. The aim of optimizing concrete mixing is to prepare concrete with best possible packing. The amount of binder (primarily cement) for filling the aggregate voids can be minimized, still keeping the freshly mixed concrete sufficiently fluid. A minimum amount of binder is beneficial not only from economical points of view but also for reducing shrinkage and creep and thereby for obtaining a product that is durable and strong. The $\mathrm{W} / \mathrm{C}$ ratio is a strength-controlling parameter that is affected by the packing concept. Particle packing models give a basis for mix designs not only for traditional concrete but also for selecting mix proportions for special concrete like high performance, self-compacting and high strength concrete [8].

\section{(1) Concepts}

The degree of packing is expressed in terms of the amount of solid aggregate minerals per unit volume (Fig. 5). The mathematical expression is simply "unity minus porosity" [9], the degree of packing being a function of the grading curve and the shape of the particles.

The packing density is determined by the following parameters for any mixture represented as [10]:

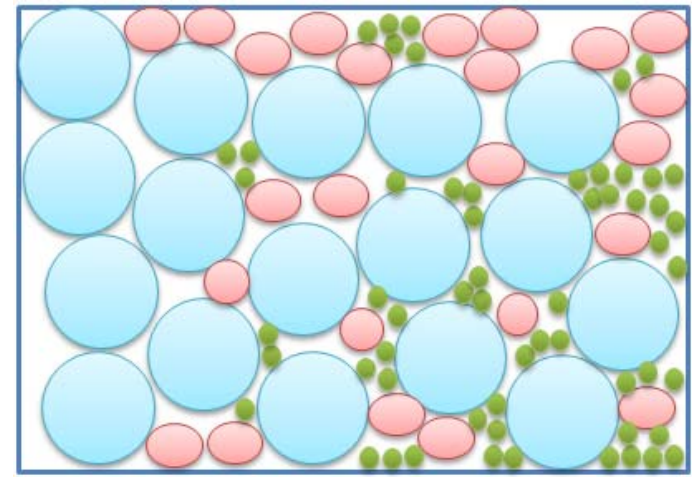

Fig. 5 Illustration of packing definition.

$V t($ total volume $)=V s$ (volume of solid particles $)+$ $V v$ (volume of voids).

Porosity $=V v / V t$

$\phi$ (packing density $)=V s / V t=1$-porosity;

(2) Packing-controlling factors

Particle packing models aim at selecting suitable sizes and proportions of small particles to fill larger voids. The small particles in turn contain smaller voids which shall be filled with smaller particles, etc.. The main factors affecting the applicability of packing theories are: (a) particle size distribution; (b) methods of compaction; (c) shape and size of particles; (d) wall effects; and (e) loosening effects.

"Wall effects" are exemplified by the function of a coarse particle located in a matrix of fine particles. This disturbs the packing of small particles along the surface of larger particles and affects the results from experimental studies using ordinary cylindrical containers and can be avoided by using containers with 10 times the diameter of the larger particle [8], as shown in Fig. 6.

"Loosening effects" are illustrated by considering the role of ("Class 2") grain located in the pores of a coarse-grain packing but not able to fit in a void, thereby decreasing the volume of (“Class 1") grains. It will disturb the packing density of coarse particles [9], as shown in Fig. 6;

(3) Impact on concrete properties by applying packing theories

Mixture proportioning of cement-based materials (such as paste composed of cement and water) and 


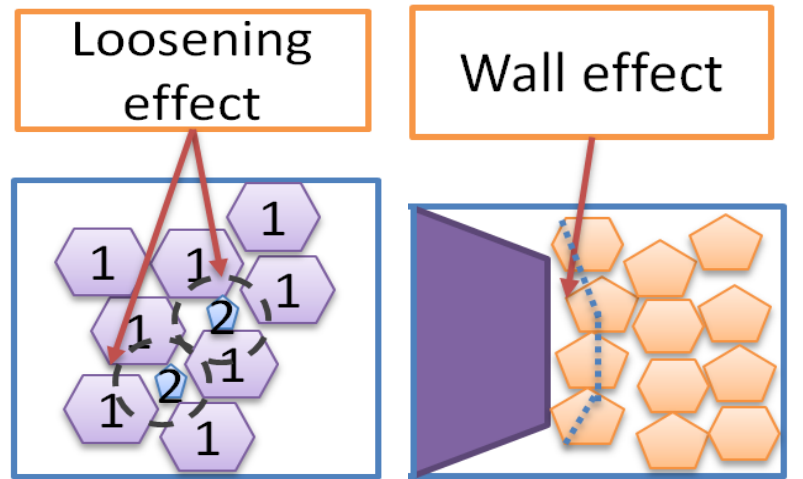

Fig. 6 Illustration of wall and loosening effects, modified from Ref. [9].

concrete can be described as a process of minimizing the volume of the voids in aggregate mixtures for obtaining the desired properties of freshly prepared and hardened material. Estimation of the packing density and the void ratio of concretes using particle packing models provide tools for optimizing their performance by reducing the content of free water and cement and maximizing the amount of solids [10].

Concrete performance is strongly affected by the particle packing degree since it determines the distribution of the cementitious component and the interaction of all mineral particles. Optimal particle packing implies minimizing the porosity and thereby reducing the amount of cement paste needed to fill the voids between the aggregate particles, taking also the rheology of the concrete into consideration. For reaching good fluidity super-plasticizers are required.

3.2.2 Practical Application of Micro-structural Modeling

(1) Theoretical evaluation of packing degree

Micro-structural parameters can be defined though statistical treatment application [11]. For the talc-concrete considered here as reference material for borehole sealing, the solid matrix consist of four major components: (a) aggregate particles; (b) cement grains; (c) talc particles; and (d) water. The aim is to define the granulometric size distribution of these components and then the packing degree for the mixture, for which the sieve curves were utilized. For the micro-structural modeling the largest grains were assumed to have an equivalent "diameter" of $1 \mathrm{~mm}$ and all aggregate grains to be tetrahedrons motivated by the angular shape caused by the crushing. Each grain had an edge length representing the "equivalent diameter" and a volume that is its base area multiplied by the height and divided by three. Its weight is the volume multiplied by $2,700 \mathrm{~kg} / \mathrm{m}^{3}$, which makes it possible to calculate the number of grains belonging to the respective size fractions and the get the packing degree by dividing the total solid volume to the total unit volume, for which the equivalent diameter was taken to be 0-0.8 mm (Fraction 1), 0.4-0.8 mm (Fraction 2) and 0-0.4 mm (Fraction 3). All particles in the respective fraction were assumed to have the same size and the number of them was calculated from the weights given by the sieve curve. The size of the quadratic REV in 2D was defined as 2,000 $\times 2,000$ $\mu \mathrm{m}^{2}$. The thickness of it was taken to be $400 \mu \mathrm{m}$ for giving fair representation of larger particles and for making it possible to include complete aggregate grains of the $0-0.4 \mathrm{~mm}$ fraction, i.e., the most important population. The distribution of tetrahedrons, representing aggregate grains of crushed quartzite, was made randomly as indicated in Fig. 4 previously. This picture is schematic and does not give the right ratios between small, medium-sized and small aggregate grains, nor the ratio between cement, aggregate or talc, but these have to be determined using packing theory, of which there are several versions;

(2) 4C-Software

4C-Packing is a model that can be used for calculating the packing of any combination of solid constituents in concrete respecting aggregate, cement, fly ash, etc. [12]. It is a linear packing model developed by employing the principles of packing of binary mixtures, extended to deal also with multi-component mixtures according to Ref. [13]. Combination of empirical model data and this packing program makes it possible to optimize the concrete composition, and at the same time, to minimize the 
cement content and thereby the cost. This software is available at the concrete center of the Danish Technological Institute [14] and has been used as a tool for comparing results from other theoretical models and from practical tests of the packing degree [15];

\section{(3) Toufar's model}

The model proposed by Ref. [16] based on the Toufar's model, has been validated by comparing around 800 test results from multiple sources. The basic and modified Toufar models are based on a number of assumptions, especially concerning the shape (perfect spheres), size variations (mono sized) and that fine and coarse aggregates are of different size [5]. They are corrected by introducing a characteristic diameter for the aggregate particles and by using the measured "Eigen-packing” (loose filling) degrees for the aggregates according to Ref. [16]. Moreover, the void diameter is a key parameter for the particle distribution and should be the basis for ascribing characteristic diameters to the aggregate particles [17].

\section{Practical Example}

\subsection{General}

The criterion that the amount of cement should be at minimum but still providing a high concrete strength can be fulfilled by keeping the cement/aggregate ratio very low and using aggregate material with high internal friction. A recommended principle in composing concrete for sealing boreholes, followed also in the present project, is therefore to reduce the cement content by application of packing theory to an absolute minimum since even total loss would have a very small impact on the porosity and hydraulic conductivity. In addition to place ability, acceptable performance of the concrete to be cast in boreholes requires that its bearing capacity is sufficient to carry the load of clay plugs and additional concrete seals. Therefore, a sufficiently high compressive strength is needed both in the construction phase and in a very long time perspective. The ideal concrete recipe gives:

- increased compressive strength with time;

- good workability and fluidity;

- minimum cement and hence low cost;

- minimum cement and ideal granular composition give low compressibility and hydraulic conductivity.

\subsection{Casting of Concrete in Borehole}

Casting concrete under water to form a homogeneous body in a deep borehole involves filling the hole of a suitable concrete through a drill rod into a borehole segment confined between packers. The drill rods above the lower packer are filled with concrete. A technique used by the American oil company Chevron-Texas [18] is shown in Fig. 7. It makes use of an expandable lower packer that is lost when re-drilling the hole.

\subsection{Experimental Program}

\subsubsection{Major Issues}

The scope of the described study was to develop an optimal concrete recipe with respect to application of packing theory based on the properties included fluidity for casting in deep boreholes, and with appropriate compressive strength. Pilot testing had shown that talc can serve as super-plasticizer.

\subsubsection{Concrete Components}

The concrete seals to be made in boreholes should have a minimum amount of cement (high packing
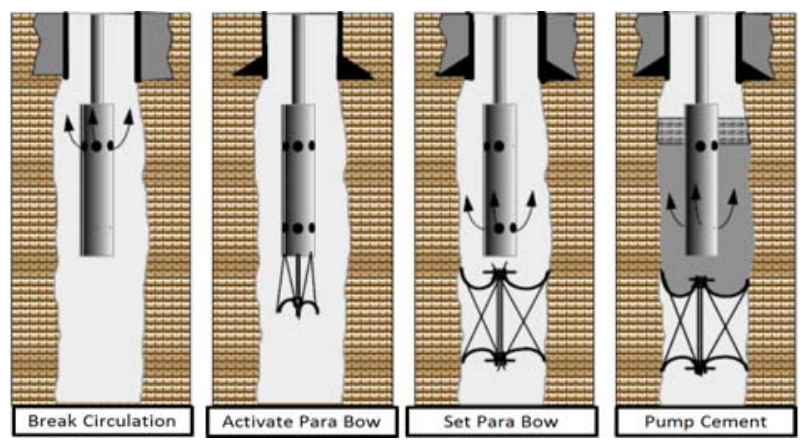

Fig. 7 The Para Bow method for cement grouting of boreholes. After re-boring that gives the hole the desired diameter, plugging is made by casting concrete or installing a clay plug (after Chevron-Texas), modified from Ref. [18]. 
density) for reducing the mutual chemical impact on the contacting clay seals. The use of talc was firstly for decreasing the viscosity of the mixture at preparation, secondly for finding out if it can contribute to the mechanical strength of the concrete by chemical interaction with the cement component, and finally to see how it affects to the whole mixture packing density.

The high mixture density which contains of low void volume needs very low content of cement and this will make the concrete sensitive to chemical and physical disturbances and the expected ultimate loss of binder will reduce the strength of the concretes. Only the aggregate grains will remain by then and for maintaining as much strength as possible, the aggregate should have a high internal friction and low void system between the particles, which was achieved by using freshly crushed quartzite as a main aggregate component. For obtaining a suitable overall grain size distribution of fuller type, adequate finer material was added in the form of fine quartz-rich sand.

(1) Materials

(a) Cement: OPC (ordinary Portland cement) and low pH cement (Merit 5000);

(b) Talc as a super plasticizer: very fine powder material with white color and the chemical formula for the mineral are $3 \mathrm{MgO} \cdot 4 \mathrm{SiO}_{2} \cdot \mathrm{H}_{2} \mathrm{O}$. This material has no negative environmental impact. It is also chemically stable in ordinary groundwater [11]. It is low-viscous, hydrophobic and does not form gels. The grain size analysis of Talc is shown in Fig. 8;

(c) Aggregate: For the tests crushed and ground quartzite was used. Crushed quartzite and ground, crushed quartzite with a specific density of 2,700 $\mathrm{kg} / \mathrm{m}^{3}$ made up the majority of the aggregate (Fig. 9). The grain size distribution of the mixture of $70 \%$ "coarse" and 30\% "fine" quartzite, which is more suitable than the 50/50 mixture was used it in all the experiments [11]. Its grain size analysis is shown in Fig. 10;

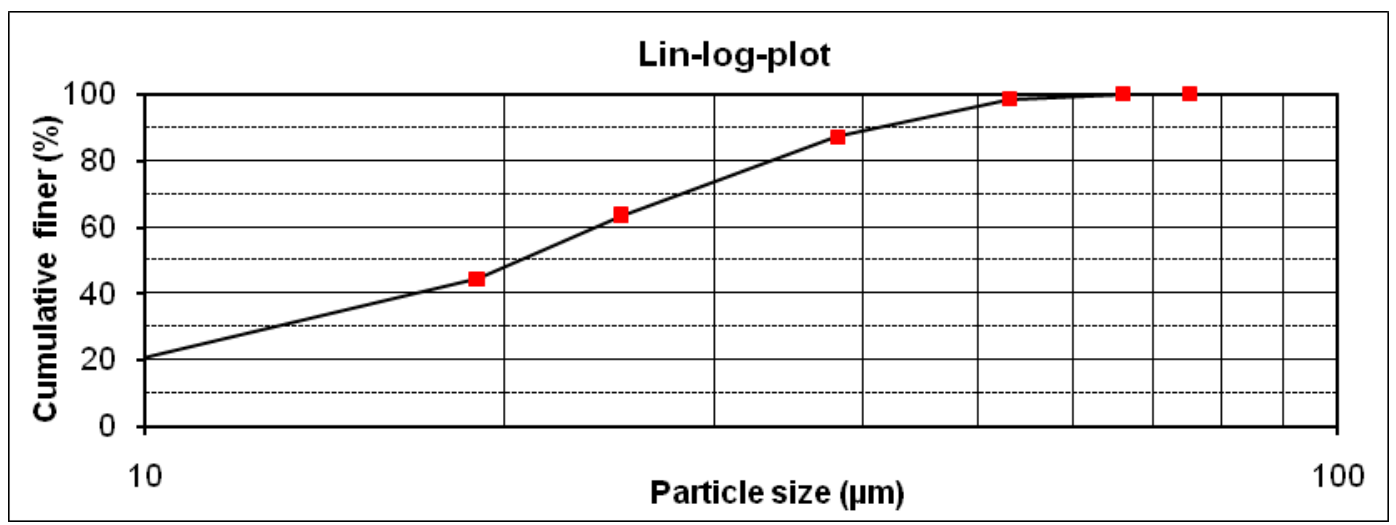

Fig. 8 Grain size analysis of talc [11].

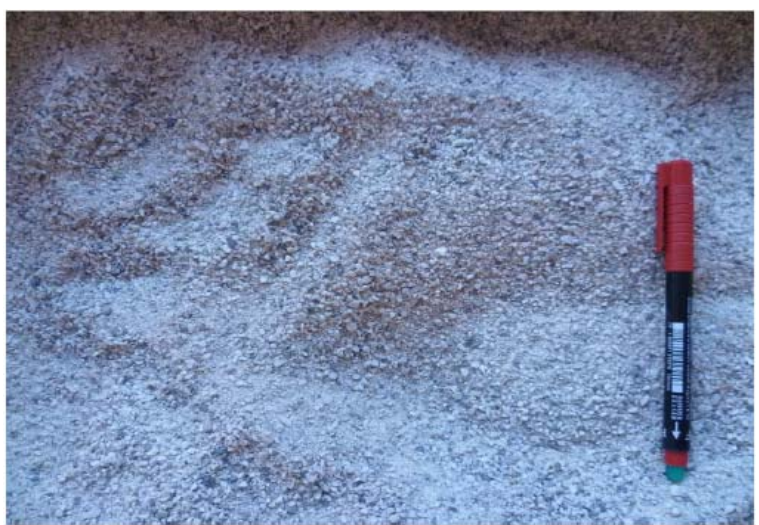

Fig. 9 Crushed quartzite. 


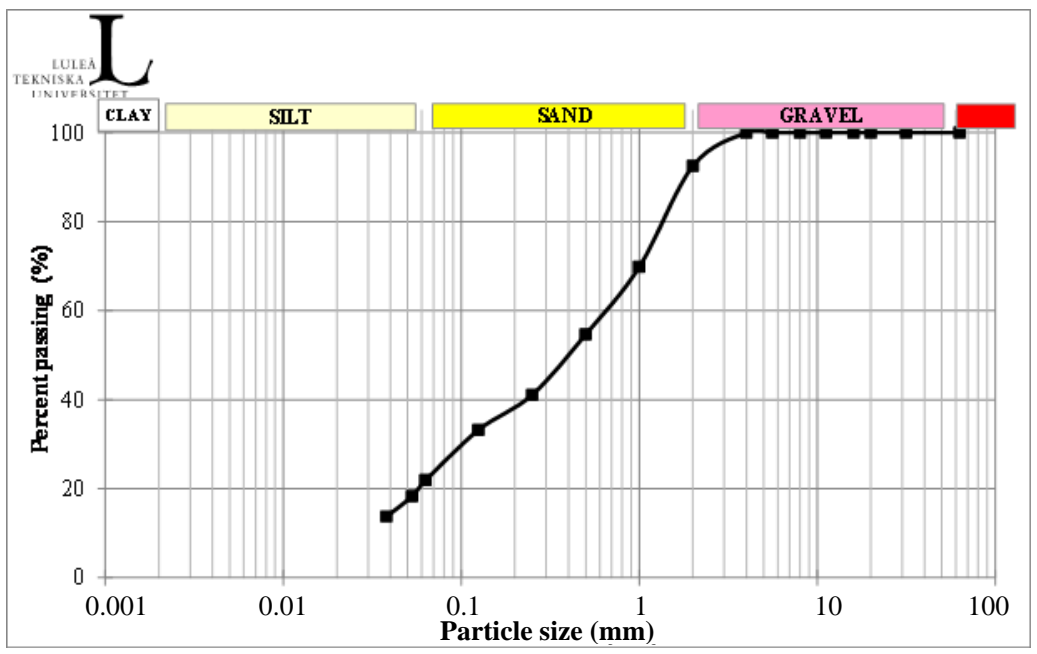

Fig. 10 Grain size analysis of aggregate mixture.

(d) Water: local water;

(2) Mixture proportions

Three concretes mixtures, one with Portland cement and two with low-pH Merit 5000 cement, were prepared by using a laboratory mixer, all with the $70 / 30$ aggregate mixture. The recipes are specified in Table 1, the intention being that the ratio of aggregate weight and water should be the same, and also the fluidity. Two or three concretes of each type were made and tested.

\subsubsection{Evaluation of the Packing Degree}

(1) Techniques

The 4C-program and Toufar's packing models were used for the evaluation of the packing degree. The "Eigen-packing" mode is one of the basic parameters and it is determined by pouring the aggregate mix into a container, evening out the surface and measuring the net weight of the material for determining the density (Fig. 11). For fulfilling the criterion for avoiding wall effects and variation in packing degree the diameter of cylinder $(50 \mathrm{~mm})$ the maximum aggregate grain size was $1 \mathrm{~mm}$. The tested materials were dried for minimizing cohesive bonds between the particles.

The packing degree, termed $\phi$ was determined according to Eq. (1).

Table 1 Mixture proportions of talc-concrete.

\begin{tabular}{|c|c|c|c|c|c|c|c|c|c|}
\hline \multicolumn{2}{|c|}{ Cement } & \multirow{2}{*}{-W/C ratio } & \multirow{2}{*}{$\begin{array}{l}\text { Water } \\
\text { content (\%) }\end{array}$} & \multirow{2}{*}{$\begin{array}{l}\text { Talc } \\
\text { (g) }\end{array}$} & \multirow{2}{*}{$\begin{array}{l}\text { Crushed } \\
\text { quartzite (g) }\end{array}$} & \multirow{2}{*}{$\begin{array}{l}\text { Ground crushed } \\
\text { quartzite (g) }\end{array}$} & \multirow{2}{*}{$\begin{array}{l}\text { Water } \\
\text { (g) }\end{array}$} & \multirow{2}{*}{$\begin{array}{l}\text { Cement } \\
\text { /aggregate ratio }\end{array}$} & \multirow{2}{*}{$\begin{array}{l}\text { Talc/aggregate } \\
\text { ratio }\end{array}$} \\
\hline Type & Weight (g) & & & & & & & & \\
\hline Portland & 100 & 4.5 & 23.34 & 220 & 1,120 & 480 & 450 & 0.062 & 0.137 \\
\hline Merit 1 & 125 & 3.6 & 23.62 & 180 & 1,120 & 480 & 450 & 0.078 & 0.113 \\
\hline Merit 2 & 250 & 1.8 & 22.17 & 180 & 1,120 & 480 & 450 & 0.156 & 0.113 \\
\hline
\end{tabular}

(a)

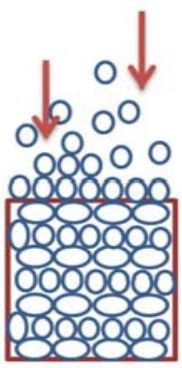

(b)

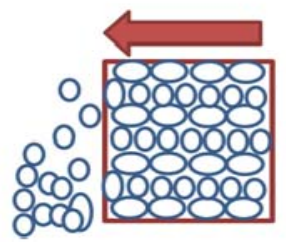

Fig. 11 Schematic shows the procedure of the test which conducted as following modified from Ref. [17]: (a) pouring of the material into the bucket and removal of the excessive; (b) weighing the material. 


$$
\phi=\frac{m_{\text {sample }}}{\rho_{\text {Agg.particle }} x V_{\text {container }}}
$$

where,

$m_{\text {sample }}$ : the weight of compacted material;

$\rho_{\text {Agg.particle: }}$ particle density;

$V_{\text {container: }}$ : volume of the test container.

The "Eigen-packing" and the packing values for different aggregate mixes were measured 2 and 3 times depending on the variance of the results. The applied method was made by using a cylinder bucket with dimensions: $H=97 \mathrm{~mm}, D=50 \mathrm{~mm}, V=190.45$ $\mathrm{cm}^{3}$ and net weight $=2.470 \mathrm{~kg}$;

(2) Experimental results

The packing degree evaluated for the concrete (Portland and Merit), mixes are shown in Table 2.

One finds that the packing degree, which is ideally unity for mixtures without empty pores, is nearly the same for the Portland and Merit 1 concretes, which also have almost the same cement contents. The Merit 2 concrete, with twice the cement content logically has a slightly lower packing degree;

(3) Results from micro-structural modeling

Using the calculated number of grains of each fraction and the numbers of talc and cement clusters belonging to the size fractions in the "pseudo 3D element” with $400 \mu \mathrm{m}$ thick elements and 2,000 $\mu \mathrm{m}$ edge lengths using the densities $\rho_{\text {talc }}=2,750 \mathrm{~kg} / \mathrm{m}^{3}$, $\rho_{\text {quartzite }}=2,650 \mathrm{~kg} / \mathrm{m}^{3}, \rho_{\text {cement }}=2,900 \mathrm{~kg} / \mathrm{m}^{3}$, one can calculate the total solid volume in the unit. After finding its solid volume, one can divide it by the total volume to get the packing degree $(\phi)$ for the mixture. Packing degrees evaluated in this way are given by Table 3.

One concludes from this that the theoretically predicted packing degree calculated on the basis of the grain size distribution of the aggregate and the various mass ratios is close to the packing degree obtained in the experiments. This is of great importance for practical application of the models used.

4.3.4 Optimum Composition of Concrete Seals in Boreholes

Optimal proportions of concrete based on cement (Portland and Merit), talc and aggregate, were determined by using 4C-program and Toufar's model as well as by the described micro-structural modeling. These models can be used for calculating the packing density of any combination of solid constituent's in concrete (aggregate, cement, etc.). Combination of empirical data and these packing models make it possible to optimize concrete composition for getting desired properties, and at the same time to minimize the cement content and consequently the price. Table 4 shows the mix proportions (actual and suggested) and maximum packing degree suggested by theoretical models for concrete based on Portland cement.

Tables 5 and 6 give corresponding data for the mixtures with Merit 5000 cement. One finds that the models suggest almost the same ratios for size fractions for obtaining a minimum void ratio.

Table 2 The results of actual packing degree for concrete mixture.

\begin{tabular}{lcclll}
\hline & \multicolumn{5}{c}{ Mix proportions (\%) } \\
\cline { 2 - 6 } Concrete type & Cement & Talc & Crushed quartzite & Ground crushed quartzite & \\
\hline Portland & 5.21 & 11.46 & 58.33 & 25 & 0.510 \\
Merit 1 & 6.56 & 9.45 & 58.8 & 25.2 & 0.515 \\
Merit 2 & 12.3 & 8.87 & 55.17 & 23.65 & 0.495 \\
\hline
\end{tabular}

Table 3 Actual packing degree and theoretical based on micro-structural modeling.

\begin{tabular}{lll}
\hline Concrete mixture & Actual packing & Theoretical packing degree based on micro-structural modeling \\
\hline Concrete (Portland) & 0.510 & 0.529 \\
Concrete (Merit 1) & 0.515 & 0.531 \\
Concrete (Merit 2) & 0.495 & 0.527 \\
\hline
\end{tabular}


Table 4 Theoretical and optimum packing degree for concrete (Portland cement).

\begin{tabular}{|c|c|c|c|c|c|c|c|}
\hline \multirow{3}{*}{ Concrete ingredients } & \multicolumn{4}{|c|}{ Packing degree $(\phi)$} & \multirow{3}{*}{$\begin{array}{l}\text {-Mix proportions } \\
\text {-suggested (\%) }\end{array}$} & \multirow{2}{*}{\multicolumn{2}{|c|}{$\begin{array}{c}\text { Packing degree }(\phi) \\
\text { Optimum }\end{array}$}} \\
\hline & \multirow{2}{*}{ Actual } & \multicolumn{3}{|c|}{ Theoretical } & & & \\
\hline & & $\overline{4 C}$ & Toufar & Microstructure & & $\overline{4 C}$ & Toufar \\
\hline Portland cement & \multirow{4}{*}{0.510} & \multirow{4}{*}{0.592} & \multirow{4}{*}{0.532} & \multirow{4}{*}{0.529} & 6 & \multirow{4}{*}{0.601} & \multirow{4}{*}{0.549} \\
\hline Talc & & & & & 8 & & \\
\hline Crushed quartzite & & & & & 60.2 & & \\
\hline Ground crushed quartzite & & & & & 25.8 & & \\
\hline
\end{tabular}

Table 5 Theoretical and optimum packing degree for concrete (Merit cement 1).

\begin{tabular}{|c|c|c|c|c|c|c|c|}
\hline \multirow{3}{*}{ Concrete ingredients } & \multicolumn{4}{|c|}{ Packing degree $(\phi)$} & \multirow{3}{*}{$\begin{array}{l}\text {-Mix proportions } \\
\text {-suggested (\%) }\end{array}$} & \multirow{2}{*}{\multicolumn{2}{|c|}{$\begin{array}{c}\text { Packing degree }(\phi) \\
\text { Optimum }\end{array}$}} \\
\hline & \multirow{2}{*}{ Actual } & \multicolumn{3}{|c|}{ Theoretical } & & & \\
\hline & & $4 \mathrm{C}$ & Toufar & Microstructure & & $4 \mathrm{C}$ & Toufar \\
\hline Merit cement (1) & \multirow{3}{*}{0.515} & \multirow{3}{*}{0.594} & \multirow{3}{*}{0.533} & \multirow{3}{*}{0.531} & 5 & \multirow{3}{*}{0.601} & \multirow{3}{*}{0.545} \\
\hline Talc & & & & & 9 & & \\
\hline Ground crushed quartzite & & & & & 25.8 & & \\
\hline
\end{tabular}

Table 6 Theoretical and optimum packing degree for concrete (Merit cement 2).

\begin{tabular}{|c|c|c|c|c|c|c|c|}
\hline \multirow{3}{*}{ Concrete ingredients } & \multicolumn{4}{|c|}{ Packing degree $(\phi)$} & \multirow{3}{*}{ Mix proportions suggested (\%) } & \multirow{2}{*}{\multicolumn{2}{|c|}{$\begin{array}{c}\text { Packing degree }(\phi) \\
\text { Optimum }\end{array}$}} \\
\hline & \multirow{2}{*}{ Actual } & \multicolumn{3}{|c|}{ Theoretical } & & & \\
\hline & & $4 \mathrm{C}$ & Toufar & Microstructure & & $4 \mathrm{C}$ & Toufar \\
\hline Merit 2 cement & & & & & 5 & & \\
\hline Talc & & & & & 9 & & \\
\hline Crushed quartzite & 0.495 & 0.455 & 0.510 & 0.527 & 60.2 & 0.601 & 0.545 \\
\hline $\begin{array}{l}\text { Ground crushed } \\
\text { quartzite }\end{array}$ & & & & & 25.8 & & \\
\hline
\end{tabular}

The theoretical packing model 4C gives the highest packing degree while the results based on Toufar's model are in better agreement with the test results (Tables 4-6). Talc powder appears to behave like cement when estimating the maximum packing density for a given content of aggregate.

\section{The Impact of the Packing Degree on the Compressive Strength}

\subsection{Scope of Study}

The packing degree is a measure of the interaction of particles representing the various concrete components. High packing degrees imply a low porosity and good fitting of the various grains and should therefore give a high strength. The compressive and tensile strengths of the concretes were determined experimentally and compared with the evaluated packing degrees.

\subsection{Determination of the Compressive Strength}

A uniaxial strength compression device was used for determining the unconfined compressive strength after 7 and 28 days. The standard procedure was followed, implying compression of the samples at a rate of $1.5 \%$ of the length per minute until failure happens. Failure of hardened concrete was interpreted as the appearance of cracks. For soft concrete with no obvious breakage, failure was taken to be the time to reach a deformation of $10 \%$ (strain) of the total length of sample. Table 7 summarizes the results from all the experiments.

One concludes that the Merit concrete gave lower compressive strength after 7 days, i.e., about 1/5 of that of the Portland concrete, while it was three times higher after 28 days [11]. This was because of chemical reactions related to dissolution of the talc material and neoformation of silicious cementing 
Table 7 Summary of compression tests results (MPa).

\begin{tabular}{|c|c|c|c|c|c|c|c|}
\hline \multirow{2}{*}{ Type of mixture } & \multirow{2}{*}{ Cement content (g) } & \multicolumn{2}{|c|}{$\begin{array}{l}\text { Average compressive } \\
\text { strength (MPa) }\end{array}$} & \multirow{2}{*}{ Actual packing degree } & \multicolumn{3}{|c|}{ Theoretical packing degree } \\
\hline & & 7 days & 28 days & & $4 \mathrm{C}$ & Toufar & Micro structural model \\
\hline Concrete (Portland) & 100 & 0.66 & 0.82 & 0.510 & 0.592 & 0.532 & 0.529 \\
\hline Concrete (Merit 1) & 125 & 0.11 & 2.63 & 0.515 & 0.594 & 0.533 & 0.531 \\
\hline Concrete (Merit 2) & 250 & 0.335 & 2.22 & 0.495 & 0.455 & 0.510 & 0.527 \\
\hline
\end{tabular}

compounds, which in fact means that the talc should be considered as a potential cementitious material.

\subsection{Relation Between Packing Degree and Compressive Strength}

Table 8 shows that the Portland and Merit 1 concrete have similar packing degrees that were somewhat lower than those of the models. The Merit 2 concrete with doubled cement content gave a slightly lower packing degree in Fig. 12. The best agreement was found between the actual packing degree and the degree given by the micro-structural model. The Toufar's model is concluded to be best of the theoretical models. The 4C model gives data that are in general agreement with experiments but overrates the evolution of the packing degree. This was also noticed by Ref. [15]. This might be attributed to the fact that this model is more sensitive to the content of fines when compared with other models and that the impact of the shape and size distribution of aggregate grains is greater. The sensitivity of one of the input parameters used in $4 \mathrm{C}$ program is " $\mu$-value" which represents the maximum size ratio between the two particles sizes where no interaction takes place [12] might be another reason. The packing density of coarse particles will be disturbed in case of small particles located within the pores of a coarse-grain but can not fit in voids between larger ones. This is referred to as "loosening-effect" and had been quantified by this parameter [15].

Table 8 Tensile strength results from Brazilian tests (MPa).

\begin{tabular}{llllll}
\hline \multirow{2}{*}{ Type of mixture } & \multirow{2}{*}{ Tensile strength average } & \multirow{2}{*}{ Actual packing degree } & \multicolumn{3}{c}{ Theoretical packing degree } \\
\cline { 4 - 6 } & & 0.510 & 0.592 & 0.532 & 0.529 \\
\hline Concrete (Portland) & 0.045 & 0.515 & 0.594 & 0.533 & 0.531 \\
Concrete (Merit 1) & 0.105 & 0.495 & 0.455 & 0.510 & 0.527 \\
Concrete (Merit 2) & 0.465 &
\end{tabular}

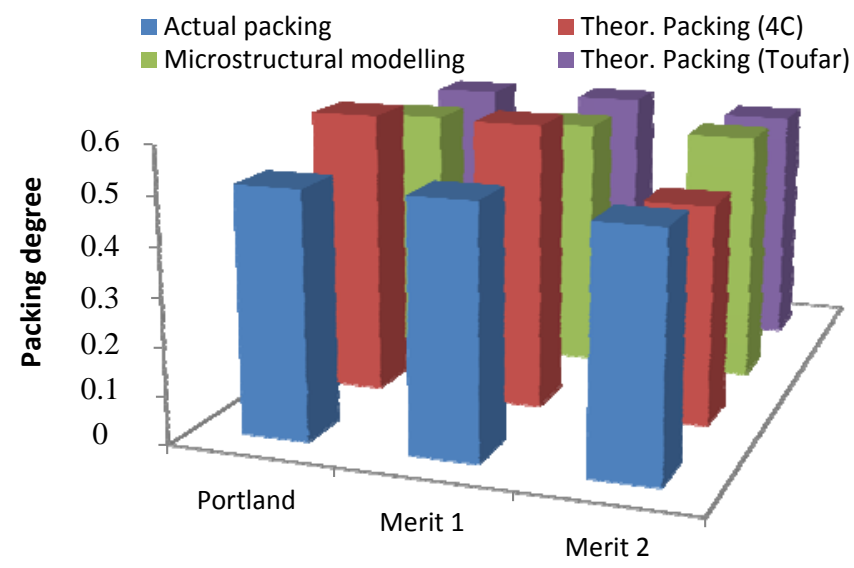

Compressive strength based concrete type

Fig. 12 Packing degrees compressive strength based type of concrete. 


\subsection{Determination of the Tensile Strength}

The Brazilian test type was used and the results interpreted as shown in Fig. 13. A disc sample is subjected to compressive loads at the disc periphery $(P)$. The disc has radius $R$ and thickness $L$ and following the standard method of ISRM (International Society for Rock Mechanics), the tensile strength, $\sigma_{t}$ is calculated from Eq. (2) [11].

$$
\sigma_{t}=\frac{P}{\pi R L}
$$

The results of the tests made after 30 days of maturation are given in Table 8. The major conclusion is that the Merit concrete was significantly stronger than Portland concrete and that the ratio of compressive and tensile strength was higher for Portland concrete than for Merit concrete [11]. The Merit concrete showed toughness and ductility after seven days but stiffer behavior after four weeks.

\subsection{Relation Between Packing Degree and Tensile Strength}

Fig. 14 shows an obvious relationship between the

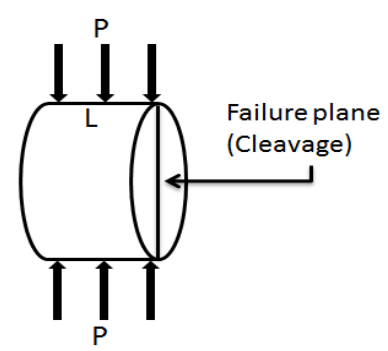

tensile strength of the three concretes and the packing degree according to the 4C model, while the other models do not exhibit this correlation. As for the compressive strength, the reason for the impact of the packing degree maybe that this model is more sensitive to the content of fines than the other models as noted previously.

A general trend is that the degree of packing increases with increasing cement content until a peak value of the packing degree is reached. Beyond this value the packing degree decreases rapidly when the quantity of cement increases. The reason may be that the "excess" cement does not establish bonds between aggregate grains but merely fills voids.

\section{Role of Talc, Cement and Aggregate Contents on the Packing Degree}

\subsection{Talc}

In principle the talc component lowers the packing degree as demonstrated by the diagrams in Fig. 15. However, it increases slightly as the ratio of talc

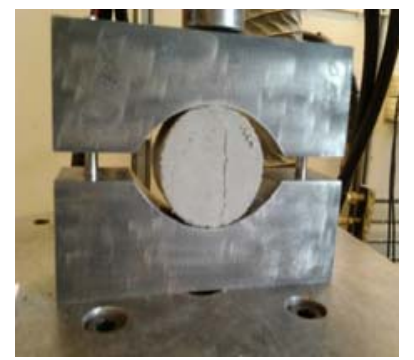

Fig. 13 Brazilian test arrangement with typical tensile fracturing [11].

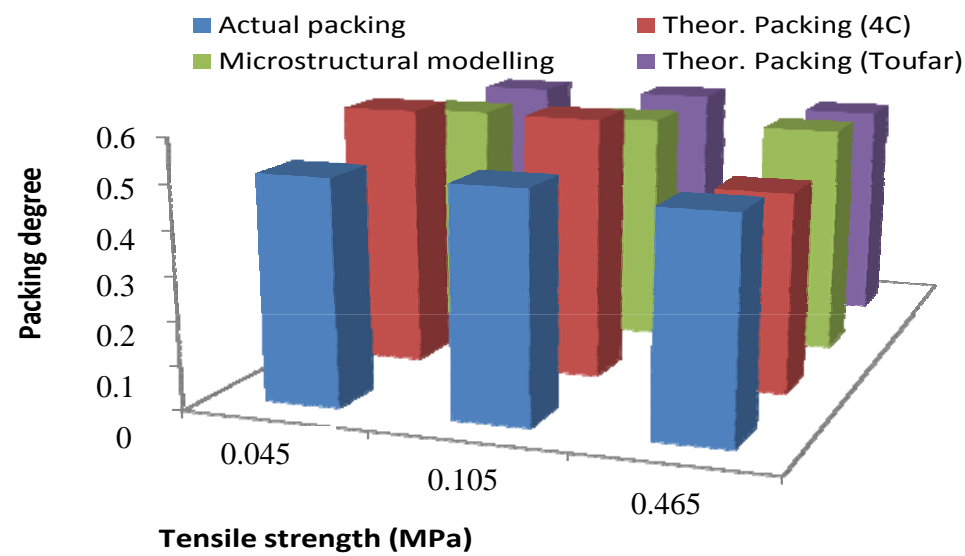

Fig. 14 Tensile strength and packing degree. 

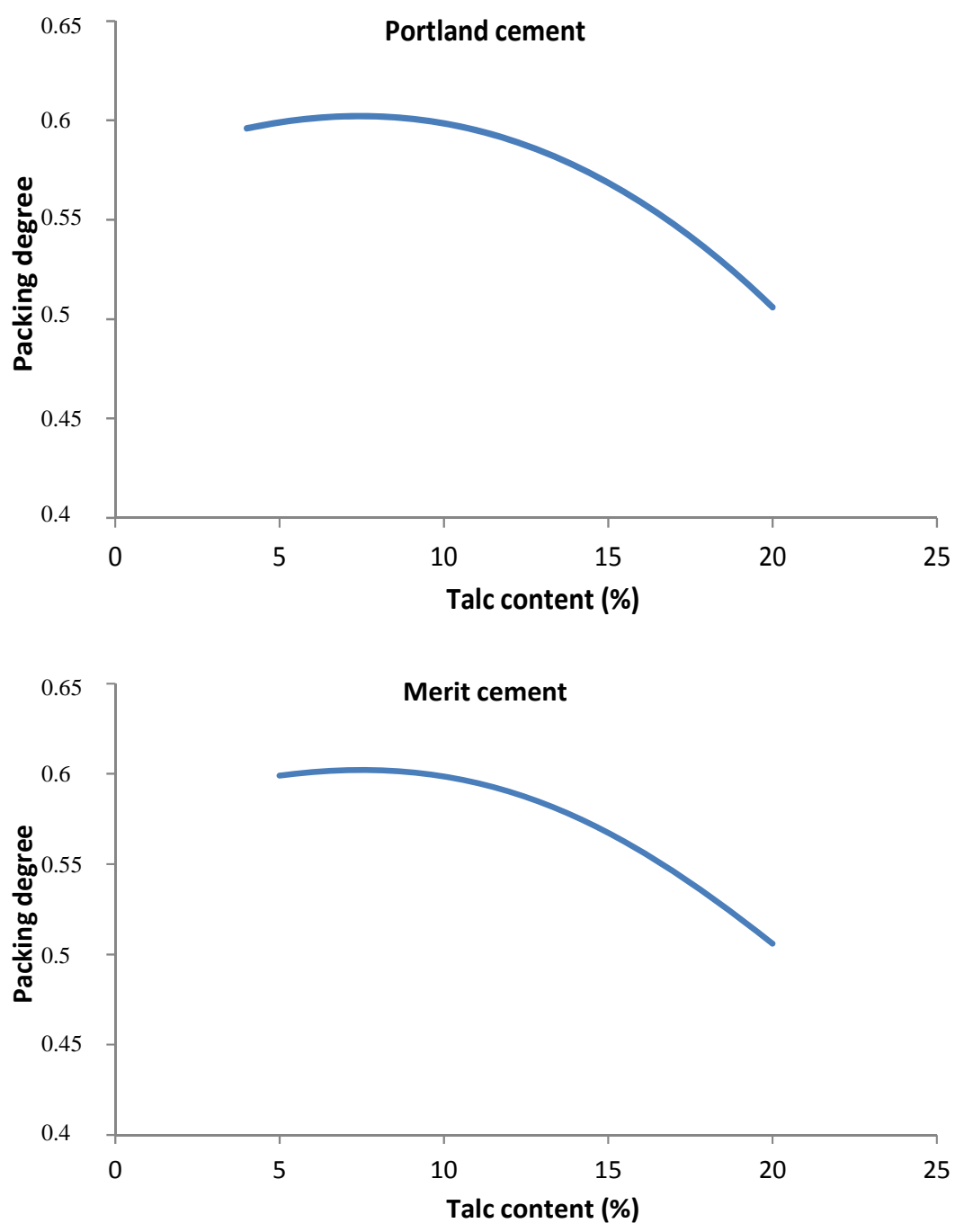

Fig. 15 Degree of packing versus content of talc in percent of the total dry weight of the concrete mixtures.

increases until a peak value is reached while it drops when the quantity of talc increases beyond this value. The graphs indicate that the optimum amount of talc ranges between $5 \%-10 \%$ of the total solid mixture content. The performance as super-plasticizer of the talc component is naturally the opposite, more talc increases the fluidity at the preparation and an optimum content is believed to be around $10 \%$.

\subsection{Aggregate}

Fig. 16 shows that the aggregate content controls the degree of packing for the concrete mixtures. The almost identical behavior of the Portland and Merit
5000 concretes at high densities, i.e., high packing degrees is explained by the very low and similar cement contents.

\subsection{Cement}

Fig. 17 shows the impact of the cement content on the packing degree as evaluated by the $4 \mathrm{C}$, Toufar and microstructural models. One finds that increasing the cement content beyond a certain value causes reduction of the packing degree and thereby the bulk density. This is interpreted as overfilling of small voids with cement, best described by the 4C model. The ideal cement content for reaching a high density would be $5 \%-10 \%$. 


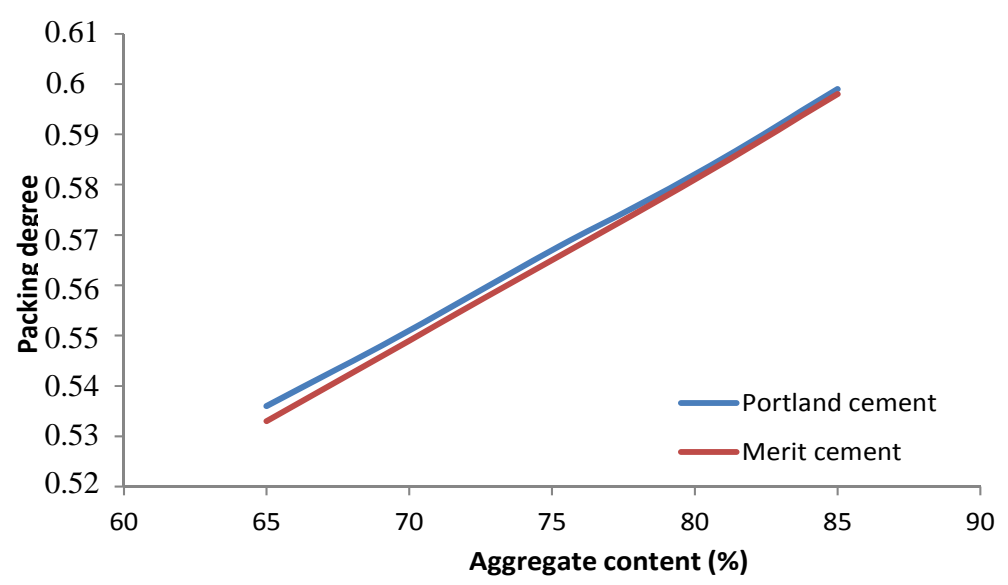

Fig. 16 Degree of packing plotted against the weight percentage of aggregate in the mixtures.

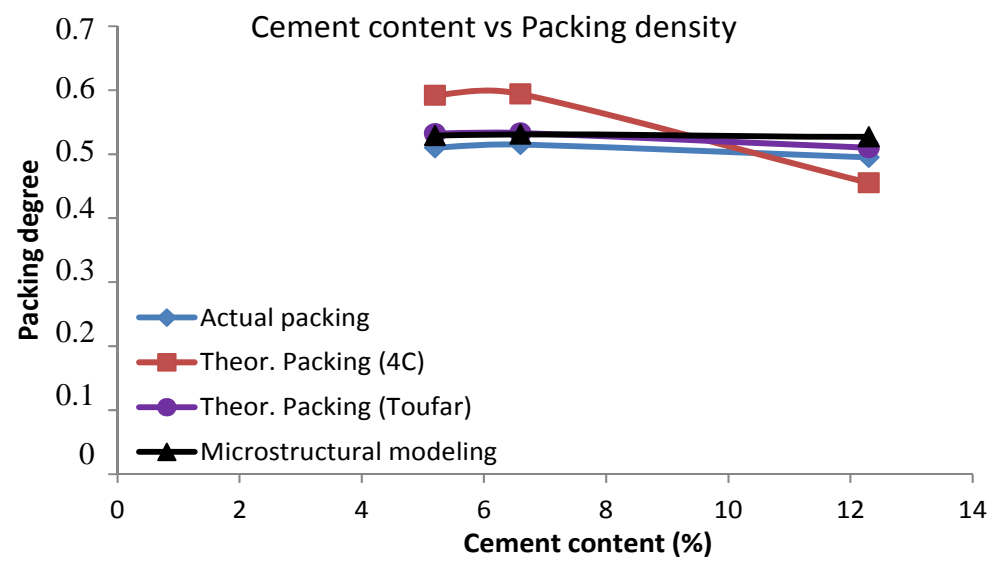

Fig. 17 Cement content in weight percent of the weight of the total amount of solids materials of the concrete mixture versus the packing degree.

\section{Discussion}

Composing the aggregate so that a sufficient amount of suitably graded fines was incorporated (70\% coarse and 30\% fine) gave effective packing and high density fulfilling the desired state of smaller particles filling the space between larger ones. The very fine-grained components, cement and talc have very small voids that need to be occupied by particles of these types representing the fine-tail of their gradation curves. Low packing degrees of the concrete mixes are caused by the "loosening effect", i.e., low degree of filling of fine voids because of oversized fine particles. This phenomenon is well known from grouting for which fine-grinding of cement to less than $5 \mu \mathrm{m}$ is desired, the problem being that moisture in the air initiates hydration and aggregation of the particles. Talc powder gives lower packing degrees than cement, which may be due to unsuitable gradation of the powder and too large talc particles.

The principle of making smaller particles occupying the void between larger ones can be followed by balancing the contents of coarse and fine particles, especially for the aggregate. This can be achieved by keeping the amount of finer material relatively low but its granulometry ideal. An important finding is that Merit cement gives higher concrete unit weight than Portland cement. The different types of cement have small impact on the packing degree. Talc powder behavior like cement with respect to the maximum packing degree for a given aggregate content. The best amount of talc additive to give high packing density 
(denser mixture) ranges between 5\%-10\% of total solid mixture content. Results based on micro-structural modeling and Toufar's model is in better agreement with experiments. The 4C model gave similar but a little overrated result concerning the evolution of packing. This implies that the $4 \mathrm{C}$ model highlights the function of the various components where the content of fine materials and the aggregate size distributions as well as the shapes are sensitive.

\section{Conclusions}

Theoretical modeling as well as experimental results confirms that concrete mixtures get high packing degrees and bulk densities if the gradation is suitable. The experiments highlight the role of the fine fraction content for making the mixture dense on all scales and lead to the following conclusions:

- Fine material gives low packing degrees by overfilling of voids because of unsuitable particle size and size distribution;

- Talc powder gives lower packing degrees than cement, probably because of poor grading. The weight percentage of talc is estimated to be $10 \%$ for reaching a reasonably high packing degree and fluidity;

- Assessment of the applicability of theoretical models indicates that Toufar's model and micro-structural modeling give results that are in more agreement with average experimental results, while the 4C program gave overrates of results even though the Eigen-packing values in the software were taken from the same experiments. This implies that the $4 \mathrm{C}$ model is highly sensitive to the content of fine materials and aggregate size distribution and it highlights the function of the various components and shapes. It can also be concluded from the results that the packing is a function of the particles shapes and the grading curve;

- Merit concrete gave lower compressive strength than Portland concrete early after preparation but much higher strength after a few weeks, indicating that the cement successively interacted with the talc causing dissolution of the first mentioned and formation of new cementing agents. This would suggest that both the cement and talc components should be increased somewhat for providing high strength of matured concrete. The role of the distribution of cement and talc particles may well be clarified by extended micro-structural modeling;

- Merit concrete showed more tough and ductile behaviour than Portland concrete, especially early in the maturation process, but later became stiffer and more brittle. This may be advantageous for use as grout injected in soil masses like clayey earth dam cores where slow creep takes place and some ductility of grouts would be ideal.

\section{References}

[1] R. Pusch, G. Ramqvist, N. Bockgard, L. Ekman, Sealing of Investigation Boreholes, Phase 4 final report, Swedish Nuclear Fuel and Waste Management Co. (SKB), Sweden, 2011.

[2] R. Tauno, O.S. Malmi, Borehole Plugging Experiment in OL-KR24 at Olkiluoto, Posiva working report, Finland, Apr. 2006.

[3] R. Pusch, G. Ramqvist, Borehole Projects, Final report phase 3, SKB R-07-58, Swedish Nuclear Fuel and Waste Management Co., Stockholm, 2007.

[4] R. Pusch, Geological Storage of Highly Radioactive Waste: Current Concepts and Plans for Radioactive Waste Disposal, Springer-Verlag, Berlin, 2008.

[5] M. Reisi, D.M. Nejad, A numerical method to predict packing density of aggregates in concrete, Advanced Materials Research 337 (2011) 313-316.

[6] L. Warr, G. Grathoff, Sealing of Investigation Boreholes: Mineralogical and Geochemical Borehole Plug Analyses, Ernst-Moritz-Arnt-Universität Greifswald, SKB technical report, Germany, 2010.

[7] R. Pusch, L. Warr, G. Grathoff, A. Purbakhtiar, S. Knutsson, M.H. Mohammed, A talc-based cement-poor concrete for sealing boreholes in rock, Engineering Journal 5 (3) (2013) 26.

[8] K.V. Senthil, S. Manu, Particle packing theories and their application in concrete mixture proportioning: A review, Indian Concrete Journal 77 (9) (2003) 1324-1331.

[9] F.D. Larrard, Concrete Mixture Proportioning, A Scientific Approach, E \& FN Spon, London, 1999.

[10] M.H. Mohammed, M. Emborg, R. Pusch, S. Knutsson, Packing theory for natural and crushed aggregate to obtain the best mix of aggregate: Research and 
development, in: Proceedings of WASET International Conference on Civil and Construction Engineering, Stockholm, Sweden, July 2012, pp. 819-825.

[11] A. Pourbakhtiar, Pilot study of method for constructing concrete seals and fracture grouts in deep boreholes and cementitious backfills in tunnels, drifts and shafts in crystalline rock, Master Thesis, Lulea university of Technology, Scandinavia, 2012.

[12] M. Glavind, E.J. Pedersen, Packing calculations applied for concrete mix design, in: Proceedings of Creating with Concrete, University of Dundee, UK, May 1999, pp. 1-10.

[13] T. Stovall, F. DeLarrard, M. Buil, Linear packing density model of grain mixtures, Powder Technol. 48 (1) (1986) $1-12$.

[14] Teknologisk Institut, the Danish Technological Institute, http://www.danishtechnology.dk// (accessed Jan. 1, 2012).

[15] M.H. Mohammed, R. Pusch, N. Al-Ansari, S. Knutsson, Optimization of concrete by minimizing void volume in aggregate mixture system, Journal of Advanced Sciences and Engineering Research 2 (3) (2012) 208-222.

[16] P. Goltermann, V. Johansen, L. Palbol, Packing of aggregates: An alternative tool to determine the optimal aggregate mix, ACI Materials Journal 94 (5) (1997) 435-443.

[17] K. Norberg, Packing theory for crushed aggregates in concrete, Master Thesis, Lulea University of Technology, Sweden, 2005, p. 72.

[18] R. Pusch, G. Ramqvist, Borehole Sealing, Preparative Steps, Design and Function of Plugs-Basic Concept, SKB IPR-04-57, Stockholm, Nov. 2004. 